\title{
CORPO E ROUPA: TERRITÓRIO DA EXISTÊNCIA E DA CULTURA. REFLEXÕES PARA 0 REDESENHO DO CORPO FEMININO NO SÉCULO XIX
}

Maria Alice Ximenes ${ }^{1}$

Discutir sobre o corpo significa esbarrar num dos temas mais contemporâneos e polêmicos da atualidade e conseqüentemente a vestimenta, para a qual essa pesquisa se dirige como repercussão da leitura que se pretende fazer dele.

A partir de uma visita feita ao Museé de la Mode et du Textile, em Paris, em março de 2001, deparei-me com vitrines que exibiam saiotes, anáguas, corpetes e espartilhos, usados no decorrer da história, especialmente no século XIX, além dos engenhosos vestidos correspondentes. A indagação que me surgiu foi: quem mais influenciou na construção da estética da forma do corpo vestido?

Partindo do pressuposto de que a vestimenta apresenta através do tempo formas resultantes das influências vigentes como arte, cultura, comportamento, sociedade e política; esta pesquisa pretende investigar através da história da indumentária e da arte, o redesenho da forma anatômica feminina no decorrer do século XIX.

O corpo vestido é estendido, portanto, passível de ser entendido, e a inquietação que move essa pesquisa é de estabelecer associações entre as pinturas dos nus e de damas vestidas retratadas pelos pintores do realismo e impressionismo; criando portanto uma analogia com os cânones da beleza oitocentista e a representação da vestimenta conivente ao olhar masculino.

A forma do corpo feminino no decorrer da história passou por diversas mudanças, que proporcionaram redesenhos reformulando sua verdadeira anatomia. Suas reais proporções foram substituídas pela construção vestimentar, de modo ficcional e muitas vezes bizarras que ocultaram a mulher sob arquitetônicos vestidos.

O século XIX foi um palco de oscilações em vários setores, desde regimes políticos, cultura e sociedade, que mesclaram formas de pensar paradoxais. E a silhueta do corpo feminino vestido, trouxe nesse período formas variáveis, onde sua estrutura desde àquelas que lembram a antigüidade clássica até o desenho de uma ampulheta, instigaram-me a desenvolver um estudo sobre a elaboração dessas formas.

A forma do corpo vestido como objeto no espaço, e em movimento, é obtido através de sua estética tridimensional, relevos, depressões, concavidades e convexidades, que entre curvas virtuais, se movimentaram em várias partes do corpo da mulher, produzindo ora quadris imensos, ora traseiros empinados, contornos sinuosos e cinturas estranguladas.

O historiador James Laver desenvolveu um estudo sobre zonas erógenas mutáveis. O que instiga refletir sobre as mudanças causadas no corpo em função das vestes no século XIX, são as divergências com o caráter comportamental.

Com o advento da Revolução Francesa, o universo participativo feminino foi de extrema coesão com os interesses do sentimento que ganhava as ruas; ela se fez presente em manifestações públicas e junto aos sans- culotte, reivindicou mudanças, onde mistura de sexos, idades e roupas foram percebidos nas multidões. Porém, as mudanças nas vestes, possuíam

1 Doutoranda pelo Instituto de Artes da UNICAMP, docente nos Cursos de Moda Centro Universitário SENAC SP, UNISAL- Americana, Pós em Styling de Moda - Metrocamp/Campinas e Coordenadora do Curso Gestão de Negócios da Moda na Faculdade de Tecnologia Uirapuru em Sorocaba. 
apenas um significado político, e o corpo da mulher logo vestiu a forma Neo Clássica da nova República, que apesar de desprovidas de qualquer direito político foram convertidas em emblemas.

Sua conduta e comportamento exibiram as virtudes da obediência e submissão, o século da devassidão e hedonismo ficou para trás, muito embora o século XIX tenha sido conhecido como o século das infidelidades. As figuras e os papéis tendo como pano de fundo uma sociedade extremamente patriarcal, denotam novos desenhos para o corpo feminino vestido de grande incoerência, pois eles eram destacados de forma insinuante e erótica.

A economia industrial consolida-se, dando primazia ao capital financeiro em detrimento da propriedade fundiária, desencadeando o nascimento do proletariado e a sua conscientização como classe, percebendo a participação do homem comum na política.

Esses fatos revelam um breve panorama onde a figura do homem surge como principal figurante, grande empreendedor, completamente envolvido nos ideais burgueses. O oposto do século passado, que na vestimenta se percebia os dois sexos preocupados com a vaidade, no século XIX o homem se apresenta vestido de maneira sóbria e séria, o próspero homem de negócios transfere para a mulher vestida o dever de ressaltar suas riquezas e poder, como se fosse uma vitrine.

Mas passeando pelo Período Romântico, Vitoriano e 1a parte de La Belle Époque, a mulher confinada à cultura feminina em vigor, que contempla o recato e pudor, se torna esculpida sob a égide de um olhar que corporificou formas indevidas com sua atitude, possivelmente idealizadas à partir da fantasia erótica masculina.

Fantasia essa, que pode ser lida através da chegada do primeiro grande costureiro à Paris - Charles Frederic Worth, ditando formas para vestir às mulheres, portanto mulheres redesenhadas por um homem, que lhes dava subsídios não apenas de sugestões de vestuário, mas utilizava seu olhar para idealizá-las segundo o desejo masculino subjacente.

A roupagem do início do século que era condizente com o lema político desde a Revolução Francesa, muda vertigimnosamente; a burguesa se veste com vestidos que marcam cinturas que ficarão tão finas que até lhe poderão provocar a morte, graças ao espartilho, além das anáguas que à partir de 1850 começam a criar uma estética horizontal ao corpo, contemplando as ancas.

As crinolinas foram anáguas bastante satirizadas pelas charges por sua amplitude extraordinária, que pode também refletir a expansão econômica do período; mas especialmente desenhou contornos para as criaturas que habitavam mais ambientes privados do que públicos. Em seguida as anáguas passam a ter a frente reta, ficando o arredondado só no traseiro; e consagrando um corpo esculpido em letra " $\mathrm{S}$ " as anquinhas formavam glúteos enormes, pois, os volumes se concentram nas costas do vestido. A invenção dessas mulheres não era somente para os homens, como também criação destes, Charles Frederic Worth, desenhou vestidos que proporcionaram verdadeiros redesenhos para o corpo feminino, pareciam ter sido feitos para serem admirados por trás.

As anáguas, crinolinas e anquinhas foram altamente responsáveis nesse processo, pois, essas subsaias projetavam os corpos dessas "mulheres centáuricas".

Minha pesquisa se ateve mais às saias, pois a rigor, o que diferenciou a mulher dos homens através das roupas, foram as calças e saias, e o século XIX por excelência sendo dominado pelos homens, traduziunas roupas um regime de autoridade, onde o prestígio do 
homem era dado especialmente pelas calças, enquanto as saias dos vestidos, especialmente armadas, representavam sinônimo de feminilidade.

Os artistas do realismo e impressionismo retrataram as mulheres vestidas e despidas; tornando evidentes partes de seus corpos, onde as protuberâncias contemplam as preferências da época - ancas e nádegas. As banhistas trazem registros de diversos ângulos e representações de como os artistas olhavam para o corpo da mulher, muitos quadros inclusive se tornaram polêmicos e repudiados nos salões de arte.

Gustave Courbet foi o artista que ricamente prestigiou a carnalidade realista do corpo feminino, a ênfase oferecida em suas pinturas evidenciaram os glúteos de camponesas, que chegaram a ser comparadas com uma égua, devido as proporções da anca do animal. Em $A$ Fonte, verifica-se a predileção em demonstrá-las vistas pelo ângulo traseiro.

Degas tinha uma forma curiosa de olhar para o corpo feminino parecia estar sempre se comportando como um voyeur, suas banhistas pareciam sempre surpreendidas de costas, onde também as protuberâncias e concavidades são notadas.

Ingres em Banho Turco celebra a generosidade das formas arredondadas do corpo feminino, não bastando, a própria moldura Ter também a forma arredondada.

Para Renoir retratar corpos femininos era algo como elucidar a ênfase animalesca do ser humano, e desembaraçadamente deixava claro que a parte mais bela do corpo da mulher lhe parecia o traseiro. Manet pintou variados nus, apesar de muitos serem acrescidos de críticas sociais, por influência dos amigos, Bauldelaire, Proust e Zola; ainda assim a forma arredondada das ancas estiveram presentes em suas pinturas.

Embora os quadros mais famosos de Tolouse Lautrec sejam temas sobre prostitutas, cenas no Molin Rouge, há uma beleza instigante nos nus pintados por ele, que contém uma emoção melancólica, sobre a beleza perecível. Mulher nua diante do espelho, reafirma as preferências masculinas corporais, acentuando os contornos circulares das nádegas.

Pintava-se a mulher nua porque era aprazível olhar para ela, da mesma forma ocorre com a roupa, que a embeleza, propõe um novo desenho para estimular o homem, ela era concebida como objeto para ser contemplado pelo espectador masculino. A roupa instiga-o a imaginar sobre seu corpo, principalmente pelo enfoque dado às formas insinuantes decorrentes do traje como sedução erótica.

Da mesma forma, acredito nessa presença da mulher vestida no século XIX, pelo homem e para o homem, assim como na maioria das pinturas a óleo européias dos nus, o protagonista principal nunca é pintado, porque ele é o espectador diante do quadro, e tudo a ele é dirigido. A mulher oferta sua feminilidade como uma coisa a ser contemplada. A paixão sexual da mulher é minimizada para que o espectador possa sentir que ele tem o monopólio dessa paixão, a forma despida ou vestida da mulher se apresenta para estimular o homem. Confirmando essa interpretação, a socióloga Gilda de Melo Souza, em O espirito das roupas, descreve a indumentária feminina do século XIX, como objeto intermediário aos anseios reprimidos da mulher:

... sob a rígida organização das sociedades, fluem anseios psíquicos subterrâneos de que a moda pressente essa direção. Na sociedade democrática do século XIX, quando os desejos de prestígio se avolumam e crescem as necessidades de distinção e de liderança, a moda encontrará recursos infinitos de torná-los visíveis. Por outro lado, quando a curiosidade sexual se contém sob o puritanismo dos costumes de uma 
sociedade burguesa, a moda descobrirá meios de, sem ofender a moral reinante, satisfazer um impulso reprimido... (SOUZA,1987, p.25).

Através desse olhar sobre a elaboração imagética, tive confirmado meu raciocínio de que a roupa possui uma segunda natureza - pertence à um processo civilizatório. É possível ler a história do homem, através da indumentária utilizada. Elizabeth Wilson destaca a roupa como o elemento que liga o ser biológico ao ser social, e Maffesoli confirma a citação, defendendo sobre as imagens vestidas como representação de um corpo social. O objetivo proposto em minha dissertação de mestrado esteve relacionado com a investigação das formas representativas da mulher vestida no século XIX, associada com a representação feita pelos pintores, trazendo a confirmação sobre a analogia da erotização criada para a mulher vestida, segundo os desejos masculinos. Porém concluí minha pesquisa, destacando a roupa que paradoxalmente erotizava as mulheres, possibilitou-as também relacionar-se emocionalmente e comunicar-se com o mundo, tendo nesse objeto; ora um instrumento opressor, ora um instrumento libertador.

É no corpo que as metamorfoses e as metáforas se instalam, procurando reconfigurações e formas de expressão consolidando o diálogo com a cultura dominante.

Esse novo território de existência e cultura, deixou de ser objeto frívolo, efêmero, fútil; para ser lido como busca de identidade, como formas de decifrar latências e tendências, que de apenas signo icônico, de imagem ótica e objetiva, passa a receber uma valorizaação estética mais ampla, de modo a se tornar símbolo e assim se expandir comunicativamente, se perpetuando no tempo e no espaço físico e social ou seja, reafirmando o "status quo", ou reformulando-o de forma crítica.

\section{Bibliografia}

BARNARD, Malcolm. Moda e Comunicação. Rio de Janeiro: Rocco, 2003.

BAUDELAIRE, Charles; (organizador Teixeira Coelho) Sobre a Modernidade. Rio de Janeiro: Paz e Terra,1996

BECKETTT, Wendy. História da Pintura. São Paulo: Editora Ática,1997.

BERGER, John. Modos de Ver. Rio de Janeiro: Rocco,1999.

BOUCHER, François. A History of Costume in the West. Londres: Thames and Hudson, 1987.

BRADFIELD, Nancy. Costume in Detail. Women’s dress 1730-1930. London: Harrap, 1981.

CASTILHO, Kathia; GALVÃO, Diana. A moda do corpo, o corpo da moda. São Paulo: Editora Esfera, 2002.

CLARK, Kenneth. The Nude: A Study in Ideal Form. Nova York: Pantheon,1956.

CUNNINGTON, Phillis. WILLETT, C. The Historyof Underclothes. Londres: Dover, 1992.

DUMAZEDIER, Joffre. A Revolução Cultural do Tempo Livre. São Paulo: Nobel, 1994. 
FOCILLON, Henri. Vida das Formas. Rio de Janeiro: Zahar Editores,1981.

FOUCAULT, Michel. História da Sexualidade (volume I). São Paulo: Graal, 2003.

HOLLANDER, Anne. O Sexo e as Roupas. Rio de Janeiro: Rocco, 1996.

JEUDY, Henri-Pierre. O Corpo como objeto de arte. São Paulo: Estação Liberdade, 2002.

LAVER, James. A Roupa e a Moda. Uma história concisa. São Paulo: Companhia das Letras,1989.

LIPOVETSKY, Gilles. O Império do Efêmero: a moda e seu destino nas sociedades modernas. São Paulo: Companhia das Letras, 1989.

LURIE, Alison. A Linguagem das Roupas. Rio de Janeiro: Rocco, 1997.

NORBERT, Elias. O Processo Civilizatório. Rio de Janeiro: Jorge Zahar Editores, 1994.

PERROT, Michelle. História da Vida Privada, 4: da Revolução Francesa à Primeira Guerra. São Paulo Companhia das Letras, 1991.

ROWLAND-WARNE, L. Costume. Londres: Dorling Kindersley Limited, 1992.

SPROCCCATI, Sandro. Guia de História da Arte. Lisboa: Editorial Presença, 1991.

SOUZA, Gilda de Mello. O Espírito das Roupas: a moda no século dezenove. São Paulo: Companhia das Letras, 1987.

VEBLEN, Thornstein. A Teoria da Classe Ociosa. São Paulo: Editora Pioneira,1965.

WILSON, Elizabeth. Enfeitada de Sonhos. Rio de Janeiro: Edições 70, 1985.

WOLF, Naomi. O Mito da Beleza. Como as imagens são usadas contra as mulheres. Rio de Janeiro: Rocco, 1992. 


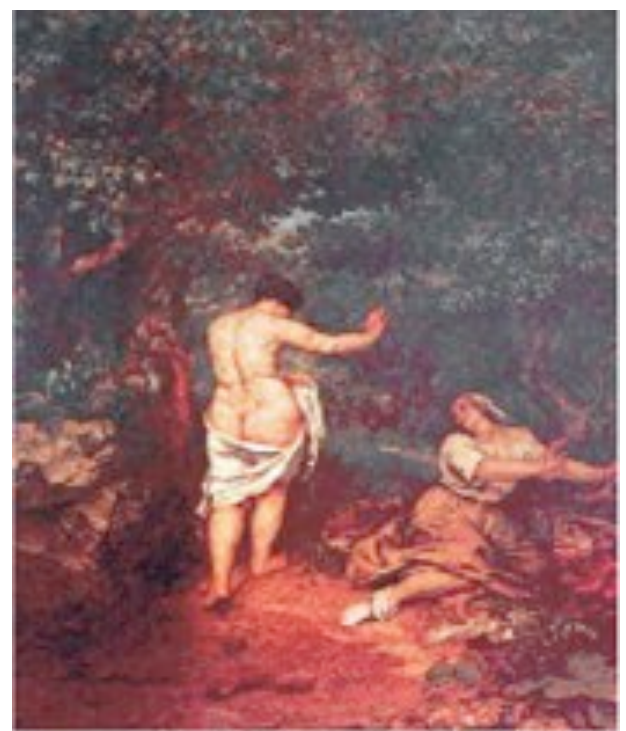

Gustave Courbet. Banhista ,1865

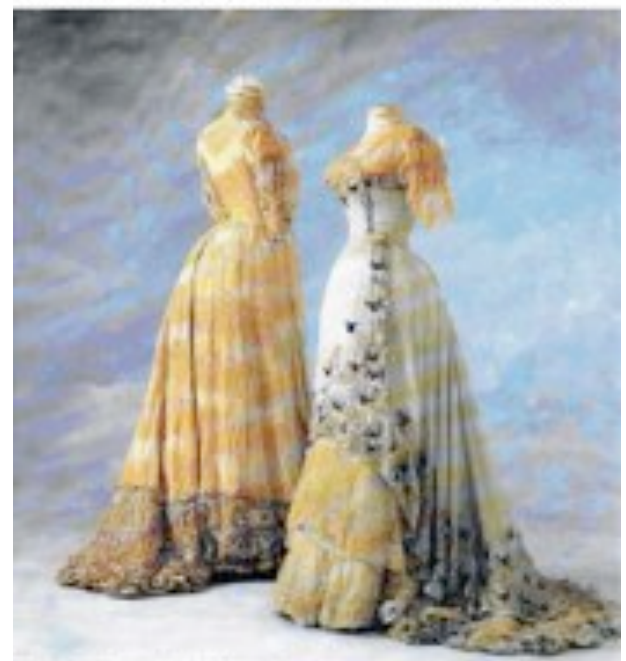

Chales Frederic Worth 